\title{
Bioconductor caAffy Q-Spline Normalization
}

National Cancer Institute

\section{Source}

National Cancer Institute. Bioconductor caAffy Q-Spline Normalization. NCI Thesaurus. Code C63934.

A method to normalize Affymetrix arrays to each other or to a set of target intensities, as defined in documents available at

http://bioconductor.org/packages/1.9/bioc/html/affy.html 